\title{
Immediate Release Tablets of Telmisartan Using Superdisintegrant- Formulation, Evaluation and Stability Studies
}

\author{
Vasanthakumar SEKAR, ${ }^{*}$ and Vijaya Raghavan ChELlan \\ Department of Pharmaceutics, College of Pharmacy, Sri Ramakrishna Institute of Paramedical Sciences; Sri Ramakrishna \\ Hospital Campus, Coimbatore-641 044, Tamil Nadu, India. $\quad$ Received May 24, 2007; accepted January 8, 2008
}

Telmisartan (anti-hypertensive) is insoluble in water; hence the drug may be slowly or incompletely dissolved in the gastro intestinal tract. So the rate of dissolution and therefore its bioavailability is less (bioavailability $42 \%$ ). In the present study an attempt has been made to prepare immediate release tablets of telmisartan by using Polyplasdone XL-10 (Crosspovidone) at intragranular, extragranular and partly intra and extragranular level of addition to increase the rate of drug release from dosage form to increase the dissolution rate and hence its bioavailability. The prepared granules and tablets were evaluated for their physiochemical properties and invitro dissolution study was conducted for the prepared tablets. It was concluded that the immediate release tablets with proper hardness, disintegration time and with increase rate of dissolution can be made using Polyplasdone XL-10. Formuation-10 (F10) was selected for stability study and the in-vitro dissolution study showed that was no difference in percent of drug released between initial and sixth month sample.

Key words intragranular; stability study; Polyplasdone XL-10; fast disintegrating tablet; telmisartan

In recent years, despite of increasing interest in controlled release drug delivery systems, more attention has been paid to formulate the poorly soluble drugs as most common tablets which intended to be swallowed to disintegrate and release their medicaments rapidly in the GIT (Gastro Intestinal Tract) or dissolution medium for better bioavailability/ dissolution. Bioavailability/rate of dissolution of the poorly soluble drug from a solid oral dosage form depends on the release of the drug substance from the drug product/dosage form $^{1-3)}$ i.e., disintegration of the solid oral dosage form which will increase the wettability of the drug by increasing the surface area of the drug particles. This highlights the importance of proper choice of disintegrant/superdisintegrant (Crosspovidone (Polyplasdone XL-10), Sodium Starch glycolate, AC- Di-Sol etc.) and its consistency of performance which are of critical importance to increase the rate of dissolution and hence its bioavailability. ${ }^{4,5)}$ There are three methods of addition of disintegrant into the formulation, intragranular (Internal Addition), extragranular (External Addition), partly intragranular and extragranular addition. ${ }^{6-8)}$

The aim of the study was to formulate immediate release tablets of Telmisartan to increase the rate of dissolution by increasing the release rate of drug from the solid oral dosage form by using different method of addition of Polyplasdone XL-10. Telmisartan was selected because of its poor solubility and less bioavailability $(42 \%) .9,10)$

\section{Experimental}

Materials Telmisartan was obtained as gift sample from Micro labs, Hosur, India. Microcrystalline cellulose (MCC), Mannitol, Sodium lauryl sulphate (SLS), Polyvinyl pyrolidine (PVP), Polyplasdone XL-10 (Crosspovidone), Magnesium stearate, Isopropyl alcohol, Dichloromethane were procured from SD fine chemicals, Mumbai and all other chemicals/solvents used were of analytical grade.

Preformulation Studies. Compatibility a) Accelerated Storage Test $\left(40 \pm 2{ }^{\circ} \mathrm{C} / 75 \pm 5 \% \mathrm{RH}\right.$ (Relative Humidity) and $\left.60 \pm 2{ }^{\circ} \mathrm{C} / 80 \pm 5 \% \mathrm{RH}\right)$ : Duplicates of drug and excipients mixture were taken in the amber colored bottle; these mixtures were kept in the accelerated storage condition in which one bottle is closed with aluminium foil and other one in an open condition. After two to four weeks, the mixtures were observed for any physical change.

b) Infrared Red Spectrum: The physical mixture of drug (Telmisartan) and excipients (Mannitol, MCC, Polyplasdone XL-10, SLS) were prepared and mixed with suitable quantity of potassium bromide. About $100 \mathrm{mg}$ of the mixture was compressed to form a transparent pellet using a hydraulic press at $15 \mathrm{t}$ pressure. It was scanned from 4000 to $400 \mathrm{~cm}^{-1}$ in Jasco FT/IR spectrophotomete. $^{11)}$

Preparation of Immediate Release Tablets by Wet Granulation All the ingredients were weighed as per formula (Table 1). Mannitol, MCC and drug were passed through sieve No. 30 and it was mixed for $15 \mathrm{~min}$ in a poly bag. Binder solution was prepared by dissolving PVP in isopropyl alcohol and dichloromethane. Granules were prepared by using PVP solution and kept for air drying. The dried granules were passed through sieve No. 20 to get uniform granules. Sodium lauryl sulphate (SLS) was passed through sieve No. 30 and mixed with above granules for $15 \mathrm{~min}$ in a poly bag. Magnesium stearate was passed through sieve No. 40 and mixed with above granules for $2 \mathrm{~min}$ in a poly bag (F1). For formulation 2, 3, and 4 Polyplasdone XL- 10 was added at $5 \%, 7.5 \%$, and $10 \%$ with mannitol and microcrystalline cellulose (intragranular) and passed through sieve No. 40. For formulation 5, 6, and 7 Polyplasdone XL-10 was added 5\%, 7.5\%, and $10 \%$ with SLS (extragranular) and sifted through sieve No. 40. For formulation 8, 9, and 10 Polyplasdone XL-10 was added partly intragranular and extragranular. Remaining procedures were the same for all formulation as like F1. The prepared granules were compressed using a single punch $(8 \mathrm{~mm}$ flat with breaking line) R \& D tablet punching machine (Kambert, Cadmach, Ahmadabad).

Evaluation of Granules and Tablets The prepared granules were evaluated for angle of repose, bulk density, tapped density, compressibility index and hausner ratio. ${ }^{12,13)}$ The prepared tablets $(\mathrm{F} 1-\mathrm{F} 10)$ were evaluated for weight variation, friability, hardness and disintegration time.

In-Vitro Dissolution Study: In-vitro drug release was determined using USP (United States Pharmacopeia) dissolution apparatus II of paddle type (TDT-08L, Electrolab) at $100 \mathrm{rpm}$ maintained at $37 \pm 0.5^{\circ} \mathrm{C}$ in $900 \mathrm{ml}$ of $0.1 \mathrm{~N} \mathrm{HCl}\left(\mathrm{pH} \mathrm{1.2)}\right.$ and Phosphate buffer $\mathrm{pH} 7.4$ as dissolution media. ${ }^{14)}$ Percent drug released was determined by taking an aliquot of $10 \mathrm{ml}$ at different time intervals $(5,10,20,30,45 \mathrm{~min})$. An equal volume of fresh dissolution medium was replaced to maintain the original volume. The samples were suitably diluted for estimating percent released by HPLC. ${ }^{15)}$

Stability Study: F10 was subjected to real time $\left(25 \pm 2{ }^{\circ} \mathrm{C} / 60 \pm 5 \% \mathrm{RH}\right)$ and accelerated stability $\left(40 \pm 2{ }^{\circ} \mathrm{C} / 75 \pm 5 \% \mathrm{RH}\right)$ test. After specified period of time (1, 2, 3, 4, 5, 6 month) samples were withdrawn and in-vitro dissolution study was conducted. Stability study was conducted as per ICH (International Conference on Harmonisation) guidelines.

\section{Results and Discussion}

An attempt was made to increase the dissolution rate of poorly soluble drug telmisartan, by using intragranular, extragranular and partly intra and extra granular addition of 
Table 1. Formulation of Immediate Release Tablets of Telmisartan

\begin{tabular}{|c|c|c|c|c|c|c|c|c|c|c|}
\hline Ingredients (mg) & $\mathrm{F} 1$ & $\mathrm{~F} 2$ & F3 & F4 & F5 & F6 & F7 & F8 & F9 & F10 \\
\hline Telmisartan & 40 & 40 & 40 & 40 & 40 & 40 & 40 & 40 & 40 & 40 \\
\hline Mannitol & 84 & 73 & 73 & 73 & 73 & 73 & 73 & 73 & 68.5 & 64 \\
\hline Micro crystalline cellulose & 43 & 44 & 44 & 44 & 44 & 44 & 44 & 44 & 44 & 44 \\
\hline Polyplasdone XL-10 (Intragranular) & - & 9 & 13.5 & 18 & - & - & - & 4.5 & 6.75 & 9 \\
\hline Polyvinyl pyrolidine & 9 & 9 & 9 & 9 & 9 & 9 & 9 & 9 & 9 & 9 \\
\hline Isopropyl alcohol and dichloromethane & qs & qs & qs & qs & qs & qs & qs & qs & qs & qs \\
\hline Polyplasdone XL-10 (Extragranular) & 1 & - & - & - & 9 & 13.5 & 18 & 4.5 & 6.75 & 9 \\
\hline Sodium lauryl sulphate & 0.36 & 0.36 & 0.36 & 0.36 & 0.36 & 0.36 & 0.36 & 0.36 & 0.36 & 0.36 \\
\hline Magnesium stearate & 3.64 & 3.64 & 3.64 & 3.64 & 3.64 & 3.64 & 3.64 & 3.64 & 3.64 & 3.64 \\
\hline
\end{tabular}

qs, quantity sufficient

Table 2. Evaluation of Granules

\begin{tabular}{|c|c|c|c|c|c|c|c|c|c|c|}
\hline Properties & $\mathrm{F} 1$ & $\mathrm{~F} 2$ & $\mathrm{~F} 3$ & $\mathrm{~F} 4$ & F5 & F6 & F7 & F8 & F9 & F10 \\
\hline $\begin{array}{l}\text { Angle } \\
\qquad \text { of repose }(\theta)^{a)}\end{array}$ & $27.93 \pm 0.39$ & $26.71 \pm 0.37$ & $26.71 \pm 0.37$ & $26.71 \pm 0.37$ & $26.73 \pm 0.87$ & $26.73 \pm 0.87$ & $26.73 \pm 0.87$ & $25.99 \pm 0.52$ & $25.99 \pm 0.52$ & $25.99 \pm 0.52$ \\
\hline $\begin{array}{l}\text { Bulk density } \\
\qquad\left(\mathrm{g} / \mathrm{cm}^{3}\right)\end{array}$ & 0.73 & 0.74 & 0.74 & 0.74 & 0.75 & 0.75 & 0.75 & 0.76 & 0.76 & 0.76 \\
\hline $\begin{array}{l}\text { Tapped density } \\
\qquad\left(\mathrm{g} / \mathrm{cm}^{3}\right)\end{array}$ & 0.79 & 0.8 & 0.8 & 0.8 & 0.81 & 0.81 & 0.81 & 0.82 & 0.82 & 0.82 \\
\hline $\begin{array}{c}\text { Compressibility } \\
\text { index }(\%)\end{array}$ & 7.5 & 7.5 & 7.5 & 7.5 & 7.4 & 7.4 & 7.4 & 7.3 & 7.3 & 7.3 \\
\hline Hausner ratio & 1.08 & 1.08 & 1.08 & 3.08 & 1.08 & 1.08 & 1.08 & 1.07 & 1.07 & 1.07 \\
\hline
\end{tabular}

a) $n=3$.

Polyplasdone XL-10 as superdisintegrant at three different concentrations of $5 \%, 7.5 \%$ and $10 \%$ (Table 1). Control tablets (F1) were prepared by the same way without Polyplasdone XL-10.

Incompatibility study, the accelerated storage test showed that there were no physical changes (colour and appearance) in the mixture after two and four weeks. There was no appearances or disappearance of peaks in the mixture spectrum (Drug and Excipients) when compared to pure drug spectrum in the IR study. These show that there was no interaction between drug and excipients. Flow properties of the granules can be judged from the angle of repose, compressibility index and hausner ratio. The angle of repose $<30^{\circ}$ indicates free flowing material and $>40^{\circ}$ with poor flow properties. The compressibility index $(\%)<10$ indicates excellent flow properties and $>38$ with poor flow properties. The hausner ratio $1.00-1.11$ indicates free flowing and $>1.60$ with poor flow properties. Values for angle of repose, compressibility index $(\%)$ and hausner ratio for all prepared granules were found to be in the range of 25.99 to $27.93^{\circ}, 7.3$ to 7.5 , and 1.07 to 1.08 which showed that the granules was free flowing and can be used for compression.

The prepared tablets were evaluated for weight variation, hardness, friability and disintegration time. Percent weight variation was observed within the limit of $\pm 7.5 \%$, which is well accepted for uncoated tablets as per USP. Since mechanical integrity is of paramount importance in successful compressed immediate release formulation, the hardness of tablets were determined and found to be in the range of 3.2 to $4.2 \mathrm{~kg} / \mathrm{cm}^{2}$. Friability was observed between 0.05 to $0.08 \%$, which were below $1 \%$ indicating the sufficient mechanical integrity and strength of the prepared tablets.

The prepared tablets were disintegrated within $15 \mathrm{~min}$, fulfilling official requirement for USP. The disintegration time
Table 3. Evaluation of Tablets

\begin{tabular}{crcr}
\hline \hline Formulation code & $\begin{array}{c}\text { Hardness } \\
\left(\mathrm{kg} / \mathrm{cm}^{2}\right)^{a)}\end{array}$ & $\begin{array}{c}\text { Friability } \\
(\%)\end{array}$ & $\begin{array}{c}\text { Disintegration time } \\
(\mathrm{min} \text { and s })^{a}\end{array}$ \\
\hline F1 & $3.2 \pm 0.10$ & 0.08 & $39.5 \pm 1.39$ \\
F2 & $3.7 \pm 0.15$ & 0.05 & $14.41 \pm 0.59$ \\
F3 & $3.7 \pm 0.06$ & 0.05 & $12.25 \pm 0.94$ \\
F4 & $3.9 \pm 0.10$ & 0.05 & $11.50 \pm 0.45$ \\
F5 & $3.9 \pm 0.10$ & 0.05 & $10.41 \pm 0.38$ \\
F6 & $3.9 \pm 0.06$ & 0.05 & $9.75 \pm 0.28$ \\
F7 & $3.9 \pm 0.10$ & 0.05 & $9.60 \pm 0.26$ \\
F8 & $4.1 \pm 0.06$ & 0.05 & $8.03 \pm 0.24$ \\
F9 & $4.2 \pm 0.10$ & 0.05 & $5.05 \pm 0.15$ \\
F10 & $4.2 \pm 0.21$ & 0.05 & $4.11 \pm 0.12$ \\
MI & $4 \pm 0.10$ & 0.08 & $7.2 \pm 0.141$ \\
\hline
\end{tabular}

a) $n=3$.

of control tablets (F1) was more $(39.5 \pm 1.39 \mathrm{~min})$. The order of disintegration was found to be increased gradually from F10 to F1. The disintegration time was found to be faster for partly intra and extragranular formulation (F10, F9, F8) when compared to extragranular (F7, F6, F5) and intragranular (F4, F3, F2) formulation (Table 3). Among extragranular and intragranular formulation, extragranular showed faster disintegration $10.41,9.75$ and $9.60 \mathrm{~min}$. Reason for faster disintegration of F10, F9 and F8 may be due to immediate disruption of the tablet into previously compressed granules by the extra granular Polyplasdone XL-10, while the disintegrating agent within the granules (intragranular) produces further erosion of the granules to the original powder particles. $^{16)}$

The in-vitro dissolution study showed, formulation F10, F9 and F8 had released maximum percent of drug $(92.9 \%$, $96.7 \%$ and $100.9 \% / 63.2 \%, 70.8 \%$ and $78.9 \%$ ) in both the dissolution medium at 45 min (Figs. 1, 2). Among extragran- 


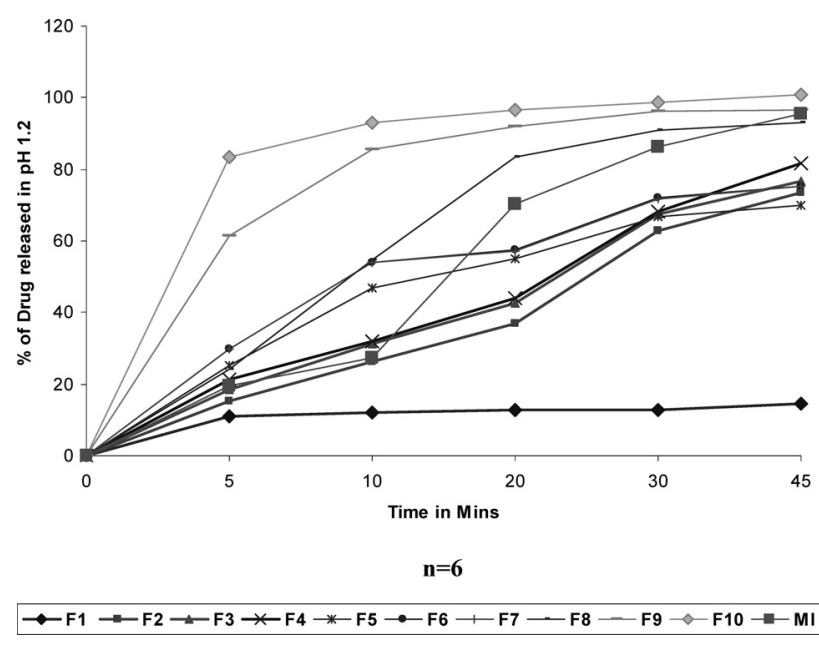

Fig. 1. In-Vitro Percent Drug Release of Telmisartan Immediate Release Tablets and Market Sample in $\mathrm{pH} 1.2$

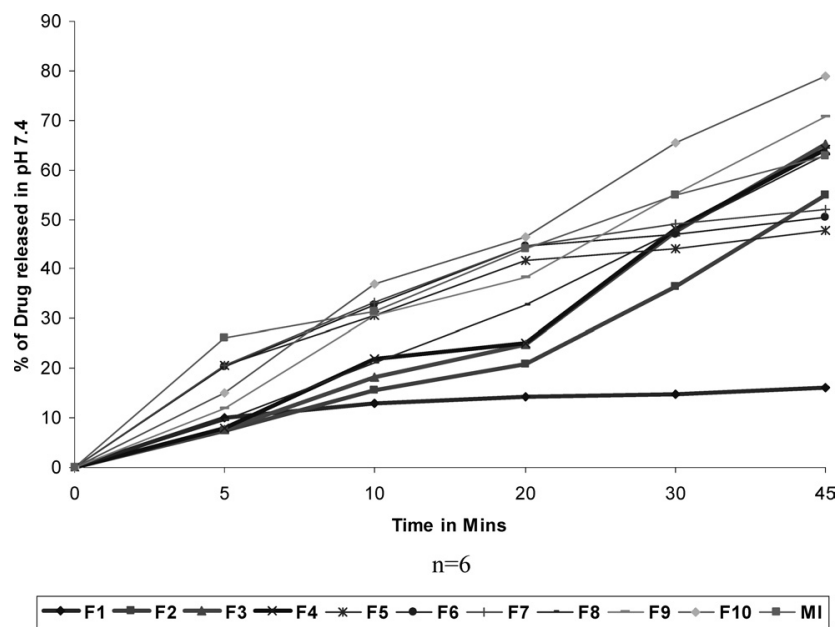

Fig. 2. In-Vitro Percent Drug Release of Telmisartan Immediate Release Tablets and Market Sample in $\mathrm{pH} 7.4$

ular and intragranular formulation, intragranular formulation showed maximum percent of drug released $(69.8 \%, 75.4 \%$, $75.1 \%$ ) in $0.1 \mathrm{~N} \mathrm{HCl}$. It showed that percent drug released was maximum in $0.1 \mathrm{~N} \mathrm{HCl}$ when compared to phosphate buffer $\mathrm{pH} 7.4$. Hence, $0.1 \mathrm{~N} \mathrm{HCl}$ was selected as dissolution medium for further studies. The possible reason for maximum percent drug released in F10, F9 and F8 may be due to increase in wettability of the drug by increasing the surface area of the drug particles (i.e., faster disintegration). When compared to market sample (MI), F10 was showing faster disintegration time and higher percent of drug release.

F10 released $90 \%$ of the drug within $8.5 \mathrm{~min}$ and $50 \%$ of the drug in $2.5 \mathrm{~min}$ (Table 4). Hence, it was selected for stability study. In-vitro dissolution results of 6th month stability sample showed that there was no significant change in drug release between initial sample (100.9\% drug release), real time sample (98.16\% drug release) and accelerated study sample (99.4\% drug release). Hence, formulation 10 was stable immediate release preparation.
Table 4. $t_{50}$ and $t_{90}$ of Telmisartan Immediate Release Tablets

\begin{tabular}{|c|c|c|c|c|}
\hline \multirow{2}{*}{$\begin{array}{l}\text { Formulation } \\
\text { code }\end{array}$} & \multicolumn{2}{|c|}{$t_{50}(\min )$} & \multicolumn{2}{|c|}{$t_{90}(\min )$} \\
\hline & $\mathrm{pH} 1.2$ & $\mathrm{pH} 7.4$ & $\mathrm{pH} 1.2$ & $\mathrm{pH} 7.4$ \\
\hline F1 & - & - & - & - \\
\hline $\mathrm{F} 2$ & 25.5 & 40 & - & - \\
\hline F3 & 22.5 & 31 & - & - \\
\hline $\mathrm{F} 4$ & 22.5 & 31 & - & - \\
\hline F5 & 14 & - & - & - \\
\hline F6 & 9 & 45 & - & - \\
\hline F7 & 9 & 33 & - & - \\
\hline F8 & 8.5 & 31 & 29 & - \\
\hline F9 & 3.5 & 27.5 & 17 & - \\
\hline F10 & 2.5 & 22.5 & 8.5 & - \\
\hline MI & 15 & - & 34 & - \\
\hline
\end{tabular}

\section{Conclusion}

In this study, the rate of dissolution of poorly soluble drug Telmisartan was increased by using Polyplasdone XL-10 as superdisintegrant. Among the three methods of addition, partly intra and extragranular addition of Polyplasdone XL10 showed faster disintegration and maximum percent of drug release. It was concluded that by using $10 \%$ of Polyplasdone XL-10, fast disintegrating stable tablets with increased rate of dissolution was prepared.

Acknowledgement Micro Labs, Hosur, India for supplying gift samples of Telmisartan and Sri Ramakrishna Institute of Paramedical Sciences, Sri Ramakrishna Hospital Campus, Coimbatore, Tamil Nadu, India for providing the necessary facilities to carry out research work.

\section{References}

1) Basak S. C., Selvin C. D. S., Sabapathy R., Indian Pharmacist, 49, $71-73$ (2006).

2) Basak S. C., Balamurugan K. S., Manavalan R., Sabapathy R., Indian Pharmacist, 43, 81-84 (2006).

3) Sangalli M. E., Giunchedi P., Colombo P., Conte U., Gazzaniga A., Manna L. A., Boll. Chim. Farm., 128, 242-247 (1989).

4) Mahajan H. S., Kuchekar B. S., Badhan A. C., Indian J. Pharm. Sci., 66, 238-240 (2004).

5) Zhao N., Larry L. A., Augsburger L. L., AAPS Pharm. Sci. Tech., 6, 79. E634-E640 (2005).

6) Momin M., Pundarikakshudu K., Indian J. Pharm. Sci., 67, 458-461 (2005).

7) Gohel M., Patel M., Amin A., Agrawal R., Dave R., Bariya N., AAPS Pharm. Sci. Tech., 5, 36. 1-6 (2004).

8) Esezobo S., J. Pharm. Pharmacol., 37, 193-195 (1985).

9) Moffat A. C., Osselton M. D., Widdop B., "Clarkel's Analysis of Drugs and Poisons," 3rd ed., Vol. II, K.M.Varghere Company, Mumbai, 2004, pp. 1601-1602.

10) Battershill A. J., Scott L. J., Drugs, 66, 51-83 (2006).

11) Rajput S. J., Shrenik S. P., Pratap A., Indian Drugs, 39, 138-141 (2002).

12) Lachman L., Liberman H. A., Kanig J. L., "The Theory and Practice of Industrial Pharmacy," 3rd ed., Varghese Publishing House, Mumbai, 1987, pp. 66-99.

13) Lindberg N., Palsson M., Pihl A., Freeman R., Freeman T., Zetzener H., Enstad G., Drug Dev. Ind. Pharm., 30, 785-791 (2004).

14) Swah R., Asgar L. F., Jain S. K., Indian J. Pharm. Sci., 67, 632-634 (2005).

15) Vijaya K. M., Muley P. R., Indian Pharmacist, 4, 69-72 (2005).

16) Uddhav S. B., Nilesh S. B., Minal S. K., Sawant S. D., Gujar K. N., Bidkar A. A., http://www.Pharmainfo.net/, Pharmainfo Web, 08 July 2006. 